\title{
TRTakademi
}

ISSN 2149-9446 | Cilt 07 | Sayı 14 | Ocak 2022 | Sosyal Medya

\section{Kovid-19 Hakkında Komplo Teorisi İçeren Dijital İçeriklerin Biçimsel Özellikleri ve Yayılım Düzeyleri Arasındaki îlişkiye Yönelik Bir Analiz}

\author{
Oğuz KUŞ*
}

\begin{abstract}
Öz
Kovid-19 aşıları hakkında komplo teorilerinin sosyal ağlarda dolaşıma girdiği bilinmektedir. Bu çalışmada kovid-19 bağlamında aşı karşıtı komplo teorilerini içeren tweetler analiz edilmiş ve tweetlerin biçimsel özellikleri ile yayılım düzeyleri arasındaki ilişki sorgulanmıştır. \#SalgınYalanAşıOlmuyorum hashtaginden toplanan 1113 tweetin biçimsel özellikleri nicel içerik analizi ile çözümlenmiş ve hipotezleri test etmek üzere Ki-kare testi uygulanmıştr. Yüksek karakter sayısı kullanım düzeyi olan tweetlerin yüksek düzeyde yayılım gösteren tweetler arasındaki payının yüksek olduğu bulunmuştur. Ayrıca bulgular düşük hashtag kullanım düzeyi ve düşük kişi etiketi kullanım düzeyine sahip tweetlerin yüksek düzeyde yayılım gösteren tweetler arasındaki payının yüksek olduğuna işaret etmektedir. Aşı karşıt tweetlerdeki bu biçimsel özellikleri anlamak aşı kabulünü artırabilecek nitelikli bilgilerin Tweetosphere'de çoğalthlabilmesi ve bu nitelikli içeriğin etkisinin artırılabilmesi için pratiğe yönelik bir önem taşımaktadır. Diğer yandan, içeriğin biçimsel boyutunun yayılımla ilişkisine ışık tutarak gelecek araştırmalarda göz önünde bulundurulabilecek yeni değişkenler sunmaktadır. Bu durum, aşı karşıtlığı ve komplo teorileri bağlamındaki araştrmaların derinleşebilmesi ve yeni çözüm önerileri sunabilmesi için bir potansiyel sunmaktadır.
\end{abstract}

Anahtar Kelimeler: Yeni Medya, Sosyal Medya, Komplo Teorileri, Kovid-19, İnfodemi

*Arş. Gör. Dr., İstanbul Üniversitesi İletişim Fakültesi Halkla İlişkiler ve Tanıtım Bölümü, oguz.kus@istanbul.edu.tr

Kuş, O. (2022). Kovid-19 Hakkında Komplo Teorisi İçeren Dijital İçeriklerin Biçimsel Özellikleri ve Yayılım Düzeyleri Arasındaki Ilişkiye Yönelik Bir Analiz. TRT Akademi, 7 (14) , 8-27. DOI: 10.37679/trta.1013649

\section{Araştırma Makalesi}

Geliş Tarihi: 22.10.2021

Revizyon Tarihi: 28.11 .2021

Kabul Tarihi: 14.01.2022

ORCID ID: 0000-0002-2593-4980 DOI: 10.37679/trta.1013649 


\title{
TRTakadeмi
}

\section{An Analysis on the Relationship Between Formal Characteristics and Diffusion Levels of Digital Content Containing Conspiracy Theories About COVID-19

\author{
Oğuz KUŞ
}

\begin{abstract}
It is known that conspiracy theories about COVID-19 vaccines are circulating on social networks. In this study, tweets containing anti-vaccine conspiracy theories in the context of COVID-19 were analyzed and the relationship between formal characteristics of tweets and their diffusion levels was questioned. Formal features of 1113 tweets collected from the hashtag \#SalgınYalanAşıOlmuyorum (\#PandemiclsLielDontGetVaccinated) were analyzed via quantitative content analysis and the Chi-square test was applied to test the hypotheses. It was found that the share of tweets with high character count usage level among tweets with high diffusion level is high. In addition, the share of tweets with low hashtag usage level and low person tag usage level among tweets with high diffusion level is high. Understanding the formal features of anti-vaccine tweets is of practical importance for producing high quality information that can increase vaccine acceptance in Tweetosphere and to increase the impact of this high quality content. On the other hand, it sheds light on the relationship between the formal dimension of content and diffusion, and offers new variables that can be considered in future research. This presents a potential for research in the context of anti-vaccine and conspiracy theories to deepen and offer new solutions.
\end{abstract}

Keywords: New Media, Social Media, Conspiracy Theories, COVID-19, Infodemic 


\section{Giriş}

Kovid-19 pandemisi ortaya çıktığından bu yana önemli miktarda can kaybına sebep olmuş, gündelik hayat pratiklerini etkilemiş ve dijital dönüşümün hız kazanmasına sebep olmuştur. Farklı çalışmalar kovid-19'un bir sonucu olarak hız kazanan dijital dönüşüme işletmeler (Soto-Acosta, 2020), çalışma şartları (Nagel, 2020), eğitim (Haslam, Madsen ve Nielsen, 2020) ve kamu hizmetleri (Agostino, Arnaboldi ve Lema, 2020) bağlamında odaklanmıştır. Dijital dönüşümün bir sonucu olarak ortaya çıkmış teknolojiler ve sosyal medya platformları kriz anlarında kolektif çözümler yaratmak üzere önemli faydalar sağlamaktadır. Bu çalışma kovid-19'u insanlığın deneyimlediği küresel bir sağlık krizi olarak kabul etmektedir. United Nations International Strategy for Disaster Reduction'ın insanlık krizi tanımına değinen Jeong ve Yeo (2017, s. 2) çalışmasında insanlık krizini “Bir topluluğun veya genellikle daha geniş bir alandaki büyük insan gruplarının sağlığına, güvenliğine, iyi olma hâline yönelik ciddi bir tehdit oluşturan bir olay veya bir olay serisi" olarak tanımlamaktadır. Kriz enformatiği alanında gerçekleştirilmiş farklı çalışmalar sosyal medyanın krizle ilgili bilgiler paylaşmak ve dijital gönüllülük faaliyetlerinde bulunmak üzere bir platform olarak kullanılabileceğine işaret etmektedir (Starbird ve Palen, 2011; Reuter vd., 2012; Abedin vd., 2014; Whittaker vd., 2015, Huang vd., 2015). Diğer yandan, sosyal medya platformlarında komplo teorilerinin, yanlış bilginin ve nitelik yönünden yetersiz bilgilerin yayılması söz konusu olabilmektedir. Kovid-19 sürecinde de yanlış bilginin dijital platformlarda dolaşıma girmesi söz konusu olmuştur. Kovid-19 pandemisi sürecinde yaşanan dijital bilgi kakofonisini infodemi olarak isimlendirmek mümkündür. Dünya Sağlık Örgütünün tanımıyla infodemi; doğru ve yanlış bilgilerin bolluğunun kafa karışıklığı yaratması, hükûmetlere ve kamu sağlığı süreçlerine yönelik güvensizliğe sebep olmasıdır (Dünya Sağlık Örgütü, 2020). Allington ve diğerleri (2020), sosyal medya platformlarını kullanmanın kovid-19 komplo teorilerine inanmayla ilişkili olduğunu ifade etmektedir.

Pandeminin üstesinden gelmek konusunda önemli araçlardan biri olan aşılar hakkında da komplo teorilerinin sosyal ağlarda sirkülasyona girdiği bilinmektedir. Aşılar hakkındaki komplo teorileri, aşıların muhteviyatından yaratabileceği yan etkilere kadar uzanan çeşitlilikte mesajlar içermektedir (Teyit.org, 2020). Freeman ve diğerleri (2020) komplo teorilerinin güvensizlik yarattğının ve aşılanmayı olumsuz etkileyebileceğinin altını çizmektedir. Kovid-19 bağlamında ortaya çıkmış olan yanlış bilgi ve komplo teorisi temelli içeriklerin mesaj ve sebep yönünden analizine yönelik farklı akademik çalışmalar yürütülmüştür. Fakat bu içeriklerin biçimsel özelliklerinin sosyal ağlarda yayılımı konusunda nasıl bir role sahip olduğuna ışık tutan çalışmaların sayısı sınırlıdır. 
Bu çalışma, kovid-19 bağlamında bir halk sağlığı tehdidi oluşturan yanlış bilgi ve komplo teorisi içeren dijital içeriklerin biçimsel özellikleri ve yayılım düzeyi arasındaki ilişkiyi keşfederek bu tip içeriklerle daha etkili mücadele edilebilmesi için iletişim perspektifinden çözüm önerileri sunmayı ve gelecek araştırmalar için düşünsel bir zemin oluşturmayı amaçlamaktadır. Bu çerçevede kovid-19 pandemisi bağlamında yanlış bilgi, komplo teorileri ve aşı karşıtlığı konularına değinilmiştir. Ayrıca dijital içeriklerin biçimsel özelliklerini keşfetmeye olanak tanıyan metin karmaşıklığı değişkenlerinden uzunluk; sosyal ağlarda etkileşimi mümkün kılan dinamiklerinden hashtag (\#) ve kişi etiketi mention (@) gibi işlevlerinin içeriğin tekrar paylaşılabilirliği/yayılımı ile olan ilişkisi irdelenmiştir. Son aşamada ise \#SalgınYalanAşıOImuyorum hashtaginden toplanan veriler analiz edilerek tweetlerin biçimsel özellikleri ve yayılımı arasındaki ilişki sorgulanmış ve çözüm önerileri sunulmuştur.

\section{Kovid-19 Bağlamında Yanlış Bilgi, Komplo Teorileri ve Aşı Karşıtı̆̆ı}

Kovid-19 pandemisinde sosyal medya platformları, otoriteler tarafindan kamu sağlığı ile ilgili bilgilerin dağıttlabilmesi için etkin bir zemin sunmuştur. Fakat yanlış bilgi, söylenti ve komplo teorileri de sosyal medyada paylaşılan kullanıcı kaynaklı içerik aracılığı ile yayılmış; bu durum pandemiyle ilgili gerekli bilgilerin dağıtılmasını, pandemiyle mücadeleyi ve pandemiyle mücadele etmek üzere alınması gereken önlemlerin adaptasyonunu olumsuz etkilemiştir.

Bu bağlamda, kovid-19 sürecinde yanlış bilgi kavramı tartışılırken komplo teorilerine değinmek önem taşımaktadır. Çünkü komplo teorileri salgınla mücadele sürecini zayıflatmakta, aşı gibi salgınla mücadele etmek üzere geliştirilmiş bilimsel araç ve önlemlerin adaptasyonunu yavaşlatmaktadır. Komplo teorilerine inanmanın temelinde stres yaratan bir olay hakkında basit bir açıklama sunması ve kontrolü tekrar ele alma hissi yaratması (Hofstadter'den aktaran Duplaga ve Grysztar, 2021) bulunmaktadır. Weigmann (2018, s. 3) tarafindan ise "komplo teorilerinin belirsizliğin baş gösterdiği durumlarda bireylerin öngörülebilirlik ve kesin sonuç ihtiyacını karşılayan basit ve tutarlı açıklamalar sunduğu" belirtilmektedir. Bu bağlamda, belirli bir kriz anında komplo teorilerinin yayılım göstermesi krizi oluşturan değişkenlerin gerçekliğinin ve tehlike potansiyelinin kavranması noktasında sorunlara sebep olma potansiyeli taşımaktadır. Pummerer ve diğerleri (2021) gerçekleştirmiş oldukları araştırmada kovid-19 ile ilgili komplo teorilerine inanmanın kurumlara güveni azalttı̆ını, resmî regülasyonlara, sosyal mesafe 
tedbirlerine uyumu bozduğunu ve belirli bir oranda toplumsal etkileşimi düşürdüğünü bulmuşlardır. Bierwiaczonek ve diğerleri (2020, s. 1282) gerçekleştirmiş oldukları araştırmanın bulguları ışığında komplo teorilerini bir toplum sağlığı tehdidi olarak nitelemektedir. Goertzel (1994), bireyin bir komplo teorisine inandığında farklı komplo teorilerine de inanmaya eğilimli olduğunu belirtmektedir. Bu bağlamda, kovid-19 hakkındaki komplo teorilerinin derinleşme potansiyeli barındıran bir halk sağlığı tehdidi olduğu tartışılabilir.

Douglas (2021), farklı araştırmacıların fikirlerine değinerek kovid-19 hakkındaki komplo teorilerinin pandeminin hemen ardından başladığının; komplo teorilerinin kaynağını gruplar arasındaki mevcut gerginliklerden aldığının altını çizmektedir. Amerika Birleşik Devletleri'ni temsil eden bir veri setinin analizi sonucunda elde edilen bulgularda katılımcıların \%29'unun kovid-19'un etkilerinin Trump'ı yıpratmak için abartıldığına; \%31'inin virüsün bir amaca hizmet etmek üzere üretilip yayıldığına inandığı belirtilmiştir (Uscinski vd., 2020). Benzer sonuçlar Türkiye'de gerçekleştirilen araştırmalarda da gözlemlenmektedir. Akyüz (2021) tarafindan gerçekleştirilmiş olan araştırmada belirtilen ifadelerden "koronavirüsün laboratuvarda üretildiği" iddiasına yüksek katılım gözlemlendiği belirtilmiştir. Diğer yandan, doğrulama platformu Teyit.org (2020), aşılarda luciferase enzimi bulunduğuna, aşıların bazı gençlerde kalp iltihaplanmasına sebep olduğuna, virüsün mutasyona uğraması sebebiyle aşıların işe yaramayacağına yönelik yanlış bilgiler saptamışlardır. Freeman ve diğerleri (2020) komplo teorilerinin güvensizlik yarattğının ve sosyal uyuma zarar vererek aşılama sürecini düşürdüğünün altını çizmektedir. Bu durum, kovid-19 ve kovid-19 aşılarıyla ilgili sosyal ağlarda üretilen ve dolaşıma giren yanlış bilgi veya komplo teorilerinin aşı karşıtlığına sebep olabileceğine işaret etmektedir.

Starbird (2020), kriz anlarında ortaya bilgi boşluklarının çıkabileceğini, bireylerin durumu anlamlandırmak üzere sosyal medyayı kullanabileceklerini, bu durumun kolektif bir anlamlandırma sürecine dönüşebileceğini ve yanlış söylentilerin ortaya çıkabileceğini ifade etmektedir. Bu bilgi boşluklarının komplo teorileriyle dolmasının aşı karşıtlığı veya önlemlere uyum sağlamamayla sonuçlanarak bir halk sağlığı tehdidine dönüşmesi muhtemeldir. Bu noktada Allington ve diğerlerinin (2020) fikirlerini göz önünde bulundurmak mümkündür. Allington ve diğerleri (2020), sosyal medya platformlarını kullanmanın kovid-19 komplo teorilerine inanmayla ilişkisi bulunduğunun altını çizmektedir. Bu bağlamda, sosyal ağların komplo teorilerinin yayılması ve görünürlüklerinin artması noktasında rol sahibi olabileceğini belirtmek mümkündür. 


\section{Sosyal Ağ İçeriklerinin Biçimsel ve Teknik Değişkenlerinin İçerik Yayılımındaki Etkisi Hakkında Bir Çerçeve}

Sosyal ağlarda dolaşıma giren yanlış bilgi veya komplo teorileri içeriklerinin barındırdığı mesaj, bu içeriği tüketen kullanıcının zihninde yarattı̆ı gerçeklik ve ona kesin olmayan bir durum karşısında sunduğu gerekçe bakımından yayılım noktasında önemlidir. Fakat yanlış bilgi taşıyan bu içeriğin yayılabilmesi ve inandırıcılık kazanması noktasında sosyal ağların sunmuş olduğu teknik olanaklar ve içeriğin biçimsel özelliklerinin rolü yadsınmamalıdır. Çünkü içeriğin sunduğu detayların benimsenmesi, farkı kullanıcıların içerikten haberdar olabilmesi veya belirli bir tema etrafindan tanınan/rastgele kullanıcıların toplandığı bir gündem yaratılabilmesi sosyal ağların sunmuş olduğu teknik özelliklerle gelişen biçimsellikle ilgilidir. Komplo teorilerinin kolay inanılabilecek gerekçelendirmeler sunarak toplumda yayılabilmesi göz önünde bulundurulduğunda; komplo teorileri içeren metinlerin biçimsel özelliklerinin ve sosyal ağların sunduğu etkileşim olanaklarının bu durumla bağlantısını sorgulamak komplo teorileriyle mücadele stratejileri geliştirmek bakımından önemlidir. Bu bağlamda sosyal medyadaki içeriklerin ilettiği mesajın anlaşılabilmesi noktasında önem taşıyan metin karmaşıkığı, farkIı kullanıcıların bir araya gelmesine olanak tanıyan kişi etiketleme (mention, @) ve hashtag (\#) gibi içeriğin biçimsel boyutlarını ifade eden değişkenlerin, sosyal ağ içeriklerinin yayılmasındaki rolünün tartşıılması önem arz etmektedir. Devam eden başılıklarda sosyal ağ içeriklerinin biçimsel özelliklerinin yayılım seviyesindeki rolünü sorgulamak üzere kavramsal bir zemin oluşturulmuştur.

\subsection{Metin Uzunluğunun Dijital Etkileşimdeki Konumuna Bir Bakış}

Valencia ve diğerleri (2004, s. 274) CCSS-ELA'nın metin karmaşıklığı modeline değinerek metin karmaşıklı̆ıını ölçmek için üç değişken olduğunu belirtmişlerdir.

Bunlar kalitatif, kantitatif ve okuyucu/görev ilintili değişkenlerdir. Kalitatif değişkenler insan okuyucular tarafindan ölçümlenebilen anlam seviyeleri, yapı, dil ve bilgi taleplerini içermektedir. Kantitatif değişkenler kelime uzunluğu veya sıklığı, cümle uzunluğu ve metin tutarlılığıdır; bu değişkenler bilgisayar programı ile etkili bir biçimde ölçümlenebilmektedir. Okuyucu/görev ilintili boyutlar ise okuyucuya bağı unsurları içermektedir. Motivasyon, bilgi, deneyim, görevin amacı veya karmaşıklığı bunlarla ilgilidir.

Bu noktadan hareketle, metinlerin uzunluğunun, metinlerin sahip olduğu karmaşıklıkla, dolayısıyla metinlerin anlaşılabilirliği ile ilintili olduğunu belirtmek 
mümkündür. Maryland State Department of Education (2013, s. 11) "cümle uzunluğu ve cümlede kullanılan kelimelerin düzeninin metin karmaşıklığını artırdığına, kısa metinlerin okunmasının kolay olduğunu, uzun metinlerin ise daha fazla fikir içerme eğilimde olduğuna" işaret etmektedir.

Metin karmaşıklığı konusunda öne sürülmüş olunan fikirlerin, özellikle kantitatif değişkenlerin, bu çalışma için önem taşıdığını belirtmek mümkündür. Çünkü bu değişkenler, sosyal medya metinlerinin kantitatif değişkenlerini incelemek noktasında ilham verici bir nitelik taşımaktadır. Sosyal medya metinlerinde biçimsel özelliklerin önemli olduğu belirtilebilir. Çünkü doğasında hızı bilgi akışı bulunan platformlarda metnin biçimsel özelliklerinin anlaşılabilirlik ve yayılım noktasında potansiyel bir değişken olması mümkündür.

Berger ve Milkman (2012) tarafindan çevrim içi içeriklerin neden yayılım gösterdiğine yönelik gerçekleştirilmiş olan araştırmada New York Times'ta yayımlanmış kimi metinler farklı faktörler ışığında değerlendirilmiştir. Uzun metinlerin daha fazla detaya değinebileceğine, bilgi içerebileceğine ve duyguları harekete geçirebileceğine işaret eden Berger ve Milkman (2012, s. 196-197) bulgularında, ünlü yazarlar tarafindan yazılmış metinlerin, kadın yazarlar tarafindan yazılmış metinlerin ve uzun metinlerin e-posta ile en fazla paylaşılan metinler arasında olduğuna yer vermiştir. Diğer yandan, Żyłka (2018) 140 karakterden uzun tweetlerin kullanıcı etkileşimi noktasında daha başarılı bir konumu olduğuna işaret etmektedir. Iqbal ve Ahmad (2021) mikro-ünlüler bağlamında gerçekleştirmiş oldukları araştırmalarında Twitter'da daha fazla etkileşimin elde edilebilmesi için kullanılabilecek maksimum miktardaki karakter sayısının kullanılması gerektiğinin altını çizmektedir. Konuyla ilgili olarak Shugars ve Beauchamp (2019) tarafindan gerçekleştirilmiş olan bir başka çalışma ise Twitter kullanıcılarının siyasal tartışmalara katılma nedenlerini ararken tweetlerin sahip olduğu kimi biçimsel özelliklere de ışık tutmaktadır. Shugars ve Beauchamp (2019, s. 9), daha fazla karakter içeren tweetlerin daha fazla cevap alma eğiliminde olduğunu belirtmektedir. Diğer yandan, Ibrahim, Wang ve Bourne (2017) tarafindan gerçekleştirilmiş olan çalışma başka faktörlere ek olarak tweetlerin uzunluğu ve tüketici duygu durumu arasında bir ilişki olduğunu ortaya koymaktadır.

Değinilen çalışmalar farklı, araştırma temalarında tweetlerin uzunluğuna yönelik çözümlemelerin gerçekleştirildiğini ve sosyal medya gönderilerinin uzunluklarının kullanıcı etkileşimiyle ilintili olabileceğini göstermektedir. Bahsi geçen araştırmalar tweetlerin uzunluğu arttıkça etkileşim miktarının arttı̆ına işaret etmektedir. Maryland State Department of Education'ın (2013) fikirleri göz önünde bulundurulduğunda uzun tweetlerin daha fazla detay ve bilgi aktarabileceğini belirtmek 
mümkündür. Bu bağlamda metin karmaşıklığı az olan tweetlerin daha az veya sığ derecede bilgi aktarabileceği, bu sebeple gerekçelendirme kapasitelerinin düşük olduğu yorumu yapılabilir. Bu durumu çalışmanın teması çerçevesinde düşündüğümüzde çalışmanın ilk hipotezini tweetlerde kullanılan karakter sayısını göz önünde bulundurarak kurmak mümkün hâle gelmektedir.

\section{2. İçeriğin Dijital Yayılımına Yönelik Biçimsel Değişkenler}

Metnin uzunluğuna ek olarak sosyal ağların sahip olduğu kullanıcı etkileşimi dinamikleri, kullanıcıların birbirleriyle etkileşime geçebilmesi, belirli bir konudan haberdar olabilmesi ve bir sosyal ağ gönderisinin taşıdığı bilginin/fikrin yayılabilmesi için önem taşımaktadır. Sosyal ağlar bireyler ve kurumları içeren bir yapıya sahiptir ve rastgele sosyal bağlantılardan aile ilişkilerini içeren bağlara kadar farklı derecelerde ilişkileri içerir (Rath, Pati ve Pattanayak, 2019, s. 21). Bu ilişkiler ağının üyeleri sosyal ağların sağlamış olduğu farklı teknik özellikler aracılığı ile etkileşime geçmektedir. Bir üyenin başka bir üyeyi etiketlemesi (örn. Twitter'da mention); belirli bir konu hakkında fikir alışverişinde bulunmaya, haberler ve olaylar hakkında bilgi, duygu ve fikirleri dağıtmaya ve organize olmaya olanak tanıyan (Chong, 2019, s. 138), tweete bağlam kazandırmak için (Tsur ve Rappaport, 2012, s. 645) veya sosyal ağlardaki konuları kategorize etmek için kullanılan hashtagler; özellikle görsel içerik temelli sosyal ağlardaki düet ve içeriği yeniden kullanım özellikleri sosyal ağ kullanıcıları arasındaki etkileşimin oluşturulması ve sürdürülmesine olanak tanımaktadır. Ayrıca, pek çok farklı platform içeriklerin tekrar paylaşılmasını mümkün kılmaktadır. Twitter da bu platformlardandır. Suh ve diğerleri (2010) retweetlemenin Twitter'daki bilgi yayılımınında anahtar bir mekanizma olduğunun, Twitter sosyal ağında basit fakat bilgi yaymak üzere güçlü bir araç olarak ortaya çıktığının altını çizmektedir.

Farklı araştırmacılar bu teknik özelliklerin bir içeriğin yayılımındaki rolünü anlamak üzere çalışmalar gerçekleştirmişlerdir. Araştırma kapsamında Twitter platformundaki paylaşımlar mercek altına alınacağından, Twitter'daki hashtag ve mention kullanımına yönelik öncül literatüre odaklanılmıştır. Kumar ve diğerlerinin $(2021$, s. 131) çalışması sahte haberlerin yayılımında hashtaglerin kullanım örüntülerine ışık tutmaktadır. Araştırmacılar sahte haberleri paylaşan kullanıcıların daha fazla hashtag ve mention kullanma eğiliminde olduğunu; hashtag kullanımının güvenilir haberlerdekine benzer bir kullanım örüntüsüne sahip olduğunu ve bu durumun daha fazla izleyicinin dikkatini çekmeye olanak tanıdığını belirtmektedirler. Suh ve diğerleri (2010, s. 183) 74 milyon tweeti inceledikleri çalışmasında, bir tweetin retweet edilmesi, hashtag ve URL içermesi arasında güçlü 
bir ilişki olduğuna işaret etmektedir. Hashtaglerin bir sosyal hareketin görünürlük kazanması ve sembolik güç elde etmesi noktasındaki işlevine odaklanan bir araşturma gerçekleştiren Wang ve diğerleri (2016) Small'un fikirlerine de değinmiş ve hashtag içeren metinlerin sade metinlere göre daha bulunabilir olduğuna işaret etmiştir. Jackson ve diğerleri (2018) ise iki ayrı hashtagden tweetlerin toplanmasıyla oluşturulan veri setini analiz etmiştir. Araştirma sonucunda bir tweetteki hashtag sayısı ve mention sayısının retweet edilme sıklığı üzerindeki etkisinin içerik veya konuya göre değişiklik gösterebileceğini saptanmıştır. Iqbal ve Ahmad (2021) tarafindan gerçekleştirilen çalışmanın sonuçlarında bir tweetin hashtag içermesinin veya bir tweette başka bir kullanıcıdan bahsedilmesinin etkileşimi artıran parametrelerden olduğu sonucuna ulaşılmıştır.

Değinilen öncül çalışmalar ışığında Twitter'da kullanılan hashtag ve başka kullanıcıları etiketleme işlevinin bir içeriğin doğru/yanlış bilgi içerse dahi yayılmasına olanak tanıdığını tartışmak mümkündür. Diğer yandan, hashtag sayısı ve etiketlenen kullanıcı sayısının retweet sayısı üzerindeki etkisinin bağlama göre değişebildiği; sahte haber paylaşan kullanıcıların daha fazla hashtag ve kişi etiketi kullanarak görünürlük elde etme eğiliminde olduğu belirtilmektedir. Bu çerçevede hashtag kullanım düzeyi ve kişi etiketi kullanım düzeyinin komplo teorisinin yayılma düzeyi ile ilişkisinin komplo teorileri de içeren aşı karşıt tweetler bağlamında test edilmesi mümkündür. Çalışma bağlamında kullanılan hashtag sayısının hashtag kullanım düzeyini, kullanılan kişi etiketi sayısının kişi etiketleme düzeyini ve retweet sayısının yayılım düzeyini belirlediği düşünüldüğünde aşağıdaki hipotezleri oluşturmak mümkün hâle gelmektedir.

\section{Amaç ve Yöntem}

Yukarıda gözden geçirilen çalışmalar göz önünde bulundurulduğunda aşağıdaki hipotezleri kurmak mümkün hâle gelmektedir:

H1. Karakter kullanım düzeyi ve komplo teorilerinin yayılım düzeyi arasında anlamlı bir ilişki mevcuttur.

H2. Hashtag kullanım düzeyi ve komplo teorilerinin yayılım düzeyi arasında anlamlı bir ilişki bulunmaktadır.

H3. Kişi etiketleme düzeyi ve komplo teorilerinin düzeyi arasında anlamlı bir ilişki bulunmaktadır. 


\subsection{Araştırma Yaklaşımı}

Bu çalışma nicel içerik analizi ile Twitter platformundan toplanan içerikleri çözümleyerek yukarıdaki hipotezleri test etmeyi, böylece sosyal ağlarda paylaşılan içeriklerin biçimsel özelliklerinin kovid-19 hakkındaki komplo teorilerinin yayılma düzeyiyle olan ilişkisini anlamayı amaçlamaktadır. İki aşamalı bir araştırma perspektifini benimseyen bu çalışmada, toplanan verilerin biçimsel özellikleri nicel içerik analizi ile çözümlenmiş, çözümleme sonucunda değişkenlere ulaşılmış ve SPSS 21 programı kullanılarak nominal veri özelliği taşıyan değişkenlere hipotezleri test etmek üzere Ki-kare testi uygulanmıştır. Araştırma kapsamında Riffe ve diğerleri (2019) tarafindan çerçevesi çizilen nicel içerik analizi yaklaşımı benimsenmiştir. Riffe ve diğerleri (2019, s. 23) nicel içerik analizi prosedürünün aşağıdaki aşamaları kapsadığına değinmektedir:

"Niceliçerik analizi, geçerli ölçümleme kuralları çerçevesinde, iletişim sembollerinin sistematik ve tekrarlanabilir bir şekilde çözümlenmesi; bu değerlerin arasındaki ilişkinin istatistiksel yöntemler kullanılarak iletişimi betimlemek, anlamları hakkında çıkarımlar yapmak veya iletişimin üretimi ve tüketimi bağlamlarından sonuçlar çıkarmak üzere analiz edilmesidir."

Diğer yandan White ve Marsh (2006, s. 36) tarafindan değinilen nicel içerik analizinin boyutlarında, kanıt oluşturmak üzere argüman temeli yaratma süreçlerinde sıklık, mevcudiyet belirleme, hipotez testi yapmaya olanak tanıyan veri gibi bileşenlere işaret edildiği gözlemlenmektedir.

Benimsenen araştırma perspektifi ve literatür taramasında zemini oluşturulan biçimsel özellikler çerçevesinde nicel içerik analizi işlemi Twitter'dan toplanan veri üzerinde gerçekleştirilmiştir. Tweetlerin biçimsel boyutlarını keşfetmek üzere gerçekleştirilen işlem, benimsenen araşttrma yöntemi perspektifindeki sistematikliği sağlamak ve tekrarlanabilir bir süreç yaratmak adına Microsoft excel işlevleri kullanılarak otomatize bir şekilde gerçekleştirilmiştir. Microsoft excel ile tweetlerde kaç adet karakterin, kaç adet hashtagin ve kaç adet kişi etiketinin mevcut olduğu saptanmıştır. Bu değerler sistematik bir şekilde, medyan değerler hesaplanarak hipotez testlerinde kullanılacak değişkenlere çevrilmiştir. Teknik detaylarına İşlem başlığında değinilen bu analiz süreci sonunda elde edilen bulgular dijital içeriklerin biçimsel özelliklerinin komplo teorilerinin yayılım düzeyi ile olan ilişkisine ışık tutmuştur.

\subsection{Veri Toplama}

Araştırma sürecinde veri toplama işlemi Twitter üzerinden gerçekleştirilmiştir. Twitter'ın gündem oluşturabilmek ve gündemi takip etmek noktasında önemli 
bir sosyal mecra hâline gelmesi; platformda, yukarıda da bahsi geçen hashtag, kişi etiketi gibi metriklerin yoğun bir şekilde kullanılması ve veri toplamak üzere etkin teknik bir zemin sunması sebebiyle araşttrma veri setinin bu mecradan toplanmasına karar verilmiştir. Veri toplama sürecinde Mozdeh Big Data Text Analysis Tool (2020) kullanılmıştr. Veri toplama işlemi Twitter'da gündem olan ve komplo teorilerine de rastlanan \#SalgınYalanAşıOlmuyorum hashtagini içeren tweetlerin, 20 Nisan 2021- 21 Nisan 2021 tarihleri arasında toplanmasıyla gerçekleştirilmiştir. Mozdeh Big Data Text Analysis aracı ve veri toplanan platformun sunduğu olanaklar çerçevesinde 5253 tweet toplanmıştir. Toplanan 5253 tweetin $\% 25$ 'i rastgele bir şekilde seçilmiştir. Devam eden süreçte, 5253 tweetin \%25'ine eşit olan 1314 tweet incelenmiş ve aşı karşıt olup olmadıkları teyit edilmiştir. Bu aşamanın ardından aşı karşıt mesajlar barındıran 1113 tweet içeren bir veri seti elde edilmiştir. Veri setinden çıkarılan 201 tweet gündemle ilişkisiz, spam ya da aynı hashtagi kullanıp aşı karşıtlığını ve komplo teorilerini eleştiren tweetlerden oluşmaktadır.

\section{3. İşlem}

Öncelikle tweetlerin sahip olduğu karakter sayısı hesaplanmıştır. Tweetlerin sahip olduğu karakter sayıları Microsoft excelin UZUNLUK işlevi kullanılarak hesaplanmıştr. Tweetlerin karakter sayısı hesaplanırken boşluklar da dâhil edilmiştir. Çünkü Twitter platformunda paylaşılan tweetlerde boşluklar 240 karakter limiti içerisinde değerlendirilmektedir. Karakter sayısının ardından tweetlerin sahip olduğu karakter sayılarının medyanı hesaplanmış ve bu sayı 189 olarak bulunmuştur. 189 'dan fazla karakter sayısına sahip olan tweetler Yüksek Karakter Kullanım Düzeyi, 189 ve daha az karakter sayısına sahip olan tweetler Düşük Karakter Kullanım Düzeyi olarak kategorize edilmiştir.

Araştırmanın ikinci hipotezini test edebilmek için tweetlerin sahip olduğu hashtag sayısı hesaplanmıştır. Bu aşamada kullanıcılar tarafindan gönderilmiş tweetlerde kaç adet "\#” işareti bulunduğu tespit edilmiştir. Bu süreçte Microsoft excelde bir hücreye \# işareti konumlandırılarak =UZUNLUK(A2)-UZUNLUK (YERi$\operatorname{NEKOY(A2;B2;))~örneğindekine~benzer~bir~formül~} 1113$ tweet için ayrı ayrı uygulanmıştr. Hashtag sayısının medyanı hesaplanmış ve bu sayı 1 olarak bulunmuştur. 1'den fazla hashtag sayısına sahip olan tweetler Yüksek Hashtag Kullanım Düzeyi, 1 ve aşağısında hashtag sayısına sahip olan tweetler Düşük Hashtag Kullanım Düzeyi şeklinde sınıflandırılmıştır. Üçüncü hipotezi test edebilmek üzere de benzer bir süreç işlenmiştir. Bu aşamada kullanıcılar tarafindan gönderilmiş tweetlerde kaç adet “@” işareti bulunduğu tespit edilmiştir. Bu süreçte Micro- 
soft excelde bir hücreye @ işareti konumlandırılarak =UZUNLUK(A2)-UZUNLUK (YERINEKOY(A2;B2;)) örneğindekine benzer bir formül 1113 tweet için ayrı ayrı uygulanmıştır. Kullanılan, kullanıcı etiketi sayılarının medyanı hesaplanmış ve bu sayı 0 olarak bulunmuştur. O'dan fazla kullanıcı etiketi sayısına sahip olan tweetler Yüksek Kullanıcı Etiketi Kullanım Düzeyi, kullanıcı etiketi kullanılmayan tweetler ise Düşük Kullanıcı Etiketi Kullanım Düzeyi şeklinde sınıflandırılmıştır. Son olarak tweetlerin almış olduğu retweet sayısının medyanı hesaplanmıştır. Retweet sayısı medyanı 37 olarak bulunmuştur. 37'den fazla retweet sayısına sahip olan tweetler Yüksek Yayılım Düzeyi, 37 ve aşağısında kullanıcı etiketi sayısına sahip olan tweetler Düşük Yayılım Düzeyi şeklinde sınıflandırılmıştır. Ardından belirlenen bu değişkenler arasındaki ilişki Ki-kare testi ile test edilmiştir.

\section{Bulgular}

Verilerin kategorizasyonu sonucunda elde edilen nominal veriler kullanılarak Ki-kare testleri gerçekleştirilmiş ve hipotezlerde değinilen değişkenler arasındaki ilişki test edilmiştir. Bu bağlamda elde edilen bulgular aşağıda paylaşılmıştır.

H1. Karakter sayısı kullanım düzeyi ve komplo teorilerinin yayılım düzeyi arasında anlamlı bir ilişki mevcuttur.

Tablo 1. Karakter Sayısı Kullanım Düzeyi ve Yayılım Düzeyini İçeren Çapraz Tablo

\begin{tabular}{|c|c|c|c|c|c|}
\hline & \multicolumn{3}{|c|}{ Yayılım Düzeyi } & \multirow{3}{*}{$\begin{array}{c}\text { Toplam } \\
\\
557 \\
\end{array}$} \\
\hline & & \multicolumn{2}{|c|}{ Düşük Yayılım Düzeyi } & $\begin{array}{c}\text { Yüksek Yayılım } \\
\text { Düzeyi }\end{array}$ & \\
\hline \multirow{4}{*}{$\begin{array}{c}\text { Karakter } \\
\text { Sayısı } \\
\text { Kullanım } \\
\text { Düzeyi }\end{array}$} & \multirow[b]{2}{*}{$\begin{array}{c}\text { Düşük Karakter } \\
\text { Sayısı Kullanım } \\
\text { Düzeyi }\end{array}$} & Sayı & 334 & 223 & \\
\hline & & $\begin{array}{c}\text { \% Karakter } \\
\text { Sayısı Kullanım } \\
\text { Düzeyi içinde }\end{array}$ & $\% 60,00$ & $\% 40,00$ & $\% 100,00$ \\
\hline & \multirow[b]{2}{*}{$\begin{array}{c}\text { Yüksek Karakter } \\
\text { Sayısı Kullanım } \\
\text { Düzeyi }\end{array}$} & Sayı & 224 & 332 & 556 \\
\hline & & $\begin{array}{l}\text { \% Karakter } \\
\text { Sayısı Kullanım } \\
\text { Düzeyi içinde }\end{array}$ & $\% 40,30$ & $\% 59,70$ & $\% 100,00$ \\
\hline \multirow{2}{*}{\multicolumn{2}{|c|}{ Toplam }} & Sayı & 558 & 555 & 1113 \\
\hline & & $\begin{array}{c}\text { \% Karakter } \\
\text { Sayısı Kullanım } \\
\text { Düzeyi içinde }\end{array}$ & $\% 50,10$ & $\% 49,90$ & $\% 100,00$ \\
\hline
\end{tabular}


Gerçekleştirilen Ki-kare testi $(2 \times 2)$ kullanıcıların \#SalgınYalanAşıOImuyorum hashtagiyle göndermiş olduğu tweetlerdeki karakter sayısı kullanım düzeyi ve komplo teorilerinin yayılım düzeyi arasında anlamlı bir ilişki olduğuna ( $\chi 2(1, N=$ $1113)=43,091, p<0.05)$ işaret etmektedir. Bu durumda $\mathrm{H} 1$ hipotezi doğrulanmıştır. Tablo 1'de değinildiği üzere daha uzun tweetlerin yüksek düzeyde yayılım gösteren tweetler arasındaki payı daha yüksektir. Düşük Karakter Sayısı Kullanım Düzeyi'ne ve Yüksek Yayılım Düzeyi'ne sahip tweetlerin yüzdesi \% 40 iken; Yüksek Karakter Sayısı Kullanım Düzeyi'ne ve Yüksek Yayılım Düzeyi'ne sahip tweetlerin yüzdesi \%59,7 olarak bulunmuştur.

H2. Hashtag kullanım düzeyi ve komplo teorilerinin yayılım düzeyi arasında anlamlı bir ilişki bulunmaktadır.

Tablo 2. Hashtag Kullanım Düzeyi ve Yayılım Düzeyini İçeren Çapraz Tablo

\begin{tabular}{|c|c|c|c|c|c|}
\hline & & \multicolumn{3}{|c|}{ Yayılım Düzeyi } & \multirow{3}{*}{$\begin{array}{c}\text { Toplam } \\
1054\end{array}$} \\
\hline & & \multicolumn{2}{|c|}{ Düşük Yayılım Düzeyi } & $\begin{array}{c}\text { Yüksek Yayılım } \\
\text { Düzeyi }\end{array}$ & \\
\hline \multirow{4}{*}{$\begin{array}{l}\text { Hashtag } \\
\text { Kullanım } \\
\text { Düzeyi }\end{array}$} & \multirow[b]{2}{*}{$\begin{array}{l}\text { Düşük Hashtag } \\
\text { Kullanım Düzeyi }\end{array}$} & Sayı & 502 & 552 & \\
\hline & & $\begin{array}{c}\text { \% Hashtag } \\
\text { Kullanım Düzeyi } \\
\text { içinde }\end{array}$ & $\% 47,6$ & $\% 52,4$ & $\% 100,0$ \\
\hline & \multirow[b]{2}{*}{$\begin{array}{l}\text { Yüksek Hashtag } \\
\text { Kullanım Düzeyi }\end{array}$} & Sayı & 56 & 3 & 59 \\
\hline & & $\begin{array}{c}\text { \% Hashtag } \\
\text { Kullanım Düzeyi } \\
\text { içinde }\end{array}$ & $\% 94,9$ & $\% 5,1$ & 1113 \\
\hline \multirow{2}{*}{\multicolumn{2}{|c|}{ Toplam }} & Sayı & 558 & 555 & 1113 \\
\hline & & $\begin{array}{c}\text { \% Hashtag } \\
\text { Kullanım Düzeyi } \\
\text { içinde }\end{array}$ & $\% 50,10$ & $\% 49,90$ & $\% 100,00$ \\
\hline
\end{tabular}

Gerçekleştirilen Ki-kare testi (2×2) kullanıcıların \#SalgınYalanAşıOlmuyorum hashtagiyle göndermiş olduğu tweetlerdeki hashtag kullanım düzeyi ve komplo teorilerinin yayılım düzeyi arasında anlamlı bir ilişki olduğuna $(\chi 2(1, N=1113)=$ $49,974, p<0.05$ ) işaret etmektedir. Bu durumda $\mathrm{H} 2$ hipotezi doğrulanmıştır. Tablo 2'de değinildiği üzere daha az hashtag kullanılan tweetlerin yüksek düzeyde yayılım gösteren tweetler arasındaki payı daha yüksektir. Yüksek hashtag Kullanım Düzeyi'ne sahip olan ve Yüksek Yayılım Düzeyi'ne sahip tweetlerin yüzdesi \%5,1 iken; Düşük Hashtag Kullanım Düzeyi’ne sahip olan ve Yüksek Yayılım Düzeyi'ne sahip tweetlerin yüzdesi \%52, 4 olarak bulunmuştur. 
H3. Kişi etiketi kullanım düzeyi ve komplo teorilerinin yayılım düzeyi arasında anlamlı bir ilişki bulunmaktadır.

Tablo 3. Kişi Etiketi Kullanım Düzeyi ve Yayılım Düzeyini İçeren Çapraz Tablo

\begin{tabular}{|c|c|c|c|c|c|}
\hline & \multicolumn{3}{|c|}{ Yayılım Düzeyi } & \multirow{3}{*}{$\begin{array}{c}\text { Toplam } \\
975 \\
\end{array}$} \\
\hline & & \multicolumn{2}{|c|}{ Düşük Yayılım Düzeyi } & \multirow{2}{*}{$\begin{array}{c}\begin{array}{c}\text { Yüksek Yayılım } \\
\text { Düzeyi }\end{array} \\
520\end{array}$} & \\
\hline \multirow{4}{*}{$\begin{array}{c}\text { Kişi Etiketi } \\
\text { Kullanım } \\
\text { Düzeyi }\end{array}$} & \multirow{2}{*}{$\begin{array}{c}\text { Düşük Kişi } \\
\text { Etiketi Kullanım } \\
\text { Düzeyi }\end{array}$} & Sayı & 455 & & \\
\hline & & $\begin{array}{c}\text { \% Kişi Etiketi } \\
\text { Kullanım Düzeyi } \\
\text { içinde }\end{array}$ & $\% 46,7$ & $\% 53,3$ & $\% 100,0$ \\
\hline & \multirow[b]{2}{*}{$\begin{array}{c}\text { Yüksek Kişi } \\
\text { Etiketi Kullanım } \\
\text { Düzeyi }\end{array}$} & Sayı & 103 & 35 & 138 \\
\hline & & $\begin{array}{c}\text { \% Kişi Etiketi } \\
\text { Kullanım Düzeyi } \\
\text { içinde }\end{array}$ & $\% 74,6$ & $\% 25,4$ & $\% 100,0$ \\
\hline \multirow{2}{*}{\multicolumn{2}{|c|}{ Toplam }} & Sayı & 558 & 555 & 1113 \\
\hline & & $\begin{array}{c}\text { \% Kişi Etiketi } \\
\text { Kullanım Düzeyi } \\
\text { içinde }\end{array}$ & $\% 50,1$ & $\% 49,9$ & $\% 100,0$ \\
\hline
\end{tabular}

Gerçekleştirilen Ki-kare testi ( 2 × 2) kullanıcıların \#SalgınYalanAşıOlmuyorum hashtagiyle göndermiş olduğu tweetlerdeki kişi etiketi kullanım düzeyi ve komplo teorilerinin yayılım düzeyi arasında anlamlı bir ilişki olduğuna $(\chi 2(1, N=1113)=$ $37,833, \mathrm{p}<0.05$ ) işaret etmektedir. Bu durumda H3 hipotezi doğrulanmıştır. Tablo 3'te değinildiği üzere daha az kişi etiketi kullanılan tweetlerin yüksek düzeyde yayılım gösteren tweetler arasındaki payı daha yüksektir. Yüksek Kişi Etiketi Kullanım Düzeyi'ne sahip olan ve Yüksek Yayılım Düzeyi'ne sahip tweetlerin yüzdesi \%25,4 iken; Düşük Kişi Etiketi Kullanım Düzeyine sahip olan ve Yüksek Yayılım Düzeyi'ne sahip tweetlerin yüzdesi \%53, 3 olarak bulunmuştur.

\section{Tartışma ve Sonuç}

Çalışmanın bulguları aşı karşıtı mesajlar taşıyan, bu mesajları taşırken yanlış bilgi ve komplo teorileri zeminine dayanan, tweetlerin biçimsel özelliklerinin sosyal ağlarda sahip oldukları yayılım düzeyiyle olan ilişkisine yönelik özgün bir perspektif sunmaktadır. Öncelikle yukarıda doğrulanmış olan hipotezler metin karmaşıkIığı bağlamında Valencia ve diğerlerinin (2004) değinmiş olduğu metnin kantitatif özelliklerinden cümle uzunluğunun komplo teorileri içeren tweetlerin yayılım düzeyini etkileyebileceğine işaret etmektedir. Araştırma kapsamında incelenen tweetlerdeki karakter sayısı kullanım düzeyi göz önünde bulundurulduğunda 
daha fazla karakter sayısına sahip olan tweetlerin daha fazla retweet edildiğini belirtmek mümkündür. Karakter sayısı kullanım düzeyi ve yayılım düzeyi ilişkisi noktasında elde edilen bu bulgu öncül çalışmaların elde etmiş olduğu bulgularla (Żyłka, 2018; Shugars ve Beauchamp, 2019) örtüşmektedir. Bu bulgu ışığında Maryland State Department of Education (2013) tarafindan alt çizilen "uzun metinlerin daha fazla fikir içerme eğiliminde olduğu" önermesi hatırlanmalıdır. Bu bağlamda daha fazla karakter kullanılan komplo teorisi içeren tweetlerde, aşı karşıtlığı ile ilgili olarak sunulan önermeye daha detaylı bir gerekçelendirme zemini oluşturulduğu; daha detaylı bir gerekçelendirmenin ise tweetin yayılımını artırma potansiyeli bulunduğu yorumu yapılabilir. Bu da komplo teorileri basit açıklamalar sunuyor olsa dahi bunu detaylı ve tutarlı şekilde anlatarak inandırıcılık kazandıkları yorumunu yapmayı mümkün kılmaktadır. Ayrıca Berger ve Milkman (2012) tarafindan öne sürülen fikirler ışığında, çalışma kapsamında incelenen daha uzun tweetlerin duyguları harekete geçirmek noktasında daha başarılı bir potansiyel taşıyor olabileceği yorumunu yapmak mümkündür.

Çalışma kapsamında incelenen veriler kapsamında kullanıcıların \#SalgınYalanAşıOlmuyorum hashtagini kullanarak komplo teorileriyle infüze olmuş aşı karşıt bir gündem oluşturduğu gözlemlenmektedir. Bu bağlamda incelenen tweetlerin çoğunun bu hashtagi içerdiği ve Tsur ve Rappaport'un (2012) belirttiği üzere tweetlere bu hashtag ile bağlam kazandırıldığı belirtilebilir. Hashtag kullanım düzeyi ve yayılım düzeyi arasındaki ilişkiye yönelik testte anlamlı bir sonuç elde edilerek hipotezin doğrulandığı; sonuçların az hashtag kullanılan tweetlerin daha yüksek düzeyde etkileşim oranına sahip olduğu gözlemlenmektedir. Bu durum genel olarak değinilen literatürle örtüşmemektedir. Bu durumun sebeplerine yönelik çift yönlü bir tartışma yürütmek mümkündür. İlk olarak Wang ve diğerleri (2016) hashtaglerin bir sosyal hareketin sembolik güç elde etmesini mümkün kıldığı noktasındaki fikirleri hatırlanmalıdır. Komplo teorisi içeren tweetlerde düşük düzeyde hashtag kullanımı, potansiyel bir şekilde kullanıcıların metnin fikirsel düzlemi konusunda hızlıca bilgi sahibi olmasını sağlayarak bir odak noktası yaratmış ve daha hızlı duygusal/fikirsel bağ kurmasına olanak tanımış olabilir. Bir diğer konu ise Twitter'ın sahip olduğu platform manipülasyonu ve spam politikası ile ilgili olabilir. Twitter (2020) bu politikada hashtag kullanımına yönelik olarak "tek bir tweette ya da birden fazla tweette aşırı sayıda ilgisiz etiket kullanarak tweetlemeyi" kötü niyetli kullanım olarak betimlemektedir. Sehl (2020) ise ikiden fazla hashtag kullanılmaması gerektiğine işaret etmektedir. Yüksek düzeyde hashtag kullanımına sahip tweetlerin büyük oranda düşük yayılım sahibi olmasını bu bağlamda düşünmek mümkündür. Son olarak kişi etiketi kullanım düzeyi ve yayılım düzeyi 
arasındaki ilişki test edilmiştir. Değişkenler arasında anlamlı bir ilişki bulunmuştur. Bulgular bağlamında daha az kişinin etiketlendiği komplo teorisi tweetlerinin daha fazla retweet edildiği yorumunu gerçekleştirmek mümkündür. Bu bağlamda kullanılan kişi etiketlerinin fazlalığının içeriğin okunabilirliğini azaltması veya kullanıcının tweetten başka kullanıcıların profiline geçmesi sonucu içerikle etkileşim kurmadığı yorumunu gerçekleştirmek mümkündür.

Araştırmanın sonuçları aşı karşıtı içerikleri tüketen ve yayılımına sebep olan kullanıcıların tükettikleri içeriklerin biçimsel boyutu hakkında, gündeme gelen aşı karşıt bir hashtag üzerinden toplanan veriler sınırlılığında, bilgi vermektedir. Diğer yandan bu araştırma, bir halk sağ|ığı tehdidi olarak tanımlanabilecek komplo teorilerinin yayılım örüntülerini anlamak üzere alana katkı sunmaktadır. Bir tweetin tekrar paylaşılması salt mesajın yayılımı olarak değil, bu tweetin mesajının kullanıcı tarafindan benimsendiğine de işaret etmektedir. Bu durum aşı adaptasyonunu sağlamak noktasında üretilecek içerikler için de yol gösterici niteliktedir. Çünkü aşı olma çağrılarını içeren içeriklerin hedef kitlesi aşı karşıt bireyleri de içermektedir, bu sebeple onların içerik tüketim örüntüleriyle örtüşen biçimsel özelliklere sahip sosyal ağ içerikleri üretmek önemlidir.

Bu bağlamda aşı karşıtı mesajlar içeren komplo teorilerinin yayılımının metnin karmaşıklığını tanımlayan biçimsel faktörlerle ilintili olduğunu; metin karmaşıklığı kavramının metin uzunluğu değişkeni perspektifinden bakıldığında daha uzun tweetlerin daha yüksek düzeyde yayılım aldığını belirtmek mümkündür. Bu metin biçiminin aşı kabulünü artırmak amacıyla dağıtılan içeriklerin etkinliğini artırmak noktasında rol oynayabileceği ifade edilebilir. Karakter sayısı fazla olan tweetler aşının avantajlarını anlatmak, komplo teorilerini çürütmek ve yanlış bilgi döngüsünü zayıflatmak üzere de kullanılabilir. Araştırma bağlamında elde edilen Yüksek Karakter Kullanım Düzeyi'ne sahip tweetlerin çoğunlukla Yüksek Yayılım Düzeyi'ne sahip olması bulgusu; ilgili organizasyonlar tarafindan aşı karşıtları arasında aşı kabulünü artırmak için detaylı ve derinlemesine bilgi içeren tweetler oluşturulduğunda hedef kitle tarafindan bu içeriğin tüketilebileceği ve yayılım gösterebileceği potansiyeli barındırıyor olabileceğine işaret etmektedir. Aşı karşıt kullanıcılardaki fazla karakter sayısına sahip, ya da detaylı içerikleri paylaşma eğilimi aşı kabulü noktasında sahip oldukları bilginin niteliğini artırmak üzere bir firsat olarak görülmelidir. Ayrıca, aşıya yönelik faydalı ve detaylı bilgiler içeren tweetlerin yayılması Tweetosphere'de bu konuya yönelik bilgi niteliğini artırma potansiyeline sahiptir. Aşı karşıt tweetlerde düşük düzeyde hashtag ve kişi etiketi sayısına sahip tweetlerin yüksek düzeyde yayılım gösterdiği yorumunu yapmak mümkündür. 
Bu durum aşı karşıt bireyleri aşı olmaya yönlendirme motivasyonuyla üretilen içeriklerin benzer biçimsel özelliklerden faydalanarak, aşı kabulü noktasında etki etme potansiyeli taşıdığına ve yayılım elde edebileceğine işaret etmektedir. Bu bağlamda aşı kabulünü vurgulayan ve sembolik bir güç yaratacak tek hashtagin kullanılması ve kişi etiketi kullanılacaksa bu etiketin resmi bilgi kaynaklarını içeren hesaplara yönlendirilmesi yorumu gerçekleştirilebilir.

Son olarak araştırmanın sınırlılıkları ve gelecek çalışmalara yönelik önerilerden bahsetmek gerekmektedir. Bu araştırma doğrudan doğruya gönderilen tweetlerin biçimsel özelliklerine, bu konuda Twitter'da gündeme gelen tek bir hashtag üzerinden veri toplayarak odaklanmaktadır. Yayılım düzeyi konusunda göz önünde bulundurulan retweet sayısı hesaplanırken kullanılan teknik olanaklar sebebiyle bir tweet, retweet edilmiş dahi olsa orijinal tweetin retweet sayısı göz önünde bulundurulmuştur. Diğer yandan, gelecek çalışmalarda daha fazla parametre araştırma sürecine dâhil edilerek ve gündem olan farklı hashtagler incelenerek komplo teorilerinin yayılımında etki sahibi olan değişkenleri anlamaya yönelik daha geniş bulguların elde edilmesi mümkündür. Komplo teorilerinin yayılımında tweetlerde paylaşılan URL sayıları, medya formatları veya kullanıcıya yönelik takipçi sayısı, takip edilen kişi sayısı gibi değişkenler komplo teorilerinin nasıl yayıldığını anlamak konusunda ve komplo teorilerine karşı yeni mücadele yöntemleri geliştirmek konusunda işlevsel olma potansiyeli taşımaktadır.

\section{Çıkar Çatışması Beyanı}

Makale yazarları herhangi bir çıkar çatışması olmadığını beyan etmiştir.

\section{Kaynakça}

Abedin, B., Babar, A., \& Abbasi, A. (2014, December). Characterization of the use of social media in natural disasters: a systematic review. In 2014 IEEE Fourth International Conference on Big Data and Cloud Computing (pp. 449-454). IEEE.

Akyüz, S. S. (2021). Aşı Karşıtlığı ve Şeffaflık Algısında İletişim Pratikleri ve Siyasal Aidiyetlerin Rolü. Yeni Medya Elektronik Dergisi, 5(2), 172-185.

Allington, D., Duffy, B., Wessely, S., Dhavan, N. ve Rubin, J. (2020). Health-protective behaviour, social media usage and conspiracy belief during the COVID-19 public health emergency. Psychological Medicine, 1-7.

Berger, J., \& Milkman, K. L. (2012). What makes online content viral?. Journal of marketing research, 49(2), 192-205. 
Bierwiaczonek, K., Kunst, J. R., \& Pich, O. (2020). Belief in COVID-19 conspiracy theories reduces social distancing over time. Applied Psychology: Health and Well-Being, 12(4), 1270-1285.

Chong, M. (2019). Discovering fake news embedded in the opposing hashtag activism networks on Twitter:\# Gunreformnow vs.\# NRA. Open Information Science, 3(1), 137-153.

Deborah Agostino, Michela Arnaboldi \& Melisa Diaz Lema (2021) New development: COVID-19 as an accelerator of digital transformation in public service delivery, PublicMoney\&Management,41:1,69-72,DOI:10.1080/09540962.2020.1764206

Douglas, K. M. (2021). COVID-19 conspiracy theories. Group Processes \& Intergroup Relations, 24(2), 270-275.

Duplaga, M. ve Grysztar, M. (2021). The Association between Future Anxiety, Health Literacy and the Perception of the COVID-19 Pandemic: A Cross-Sectional Study. Healthcare, 9(1), 43.

Dünya Sağlık Örgütü (2020). Coronavirus disease (COVID-19) Situation Report - 169. who. int/docs/default-source/coronaviruse/situation-reports/20200707covid-19-sitrep-169.pdf?sfvrsn=c6c69c88_2 adresinden alındı (Erişim Tarihi: 17.10.2021)

Freeman, D., Loe, B. S., Chadwick, A., Vaccari, C., Waite, F., Rosebrock, L., ... \& Lambe, S. (2020). COVID-19 vaccine hesitancy in the UK: the Oxford coronavirus explanations, attitudes, and narratives survey (Oceans) II. Psychological medicine, 1-15.

Goertzel, T. (1994). Belief in conspiracy theories. Political psychology, 731-742.

Haslam, C. R., Madsen, S., \& Nielsen, J. A. (2021). Crisis-driven digital transformation: Examining the online university triggered by COVID-19. In Digitalization (pp. 291-303). Springer, Cham.

Huang, Y. L., Starbird, K., Orand, M., Stanek, S. A., \& Pedersen, H. T. (2015, February). Connected through crisis: Emotional proximity and the spread of misinformation online. In Proceedings of the 18th ACM conference on computer supported cooperative work \& social computing (pp. 969-980).

Ibrahim, N. F., Wang, X., \& Bourne, H. (2017). Exploring the effect of user engagement in online brand communities: Evidence from Twitter. Computers in Human Behavior, 72, 321-338.

Iqbal Khan, S. and Ahmad, B. (2021), "Tweet so good that they can't ignore you! Suggesting posting strategies to micro-celebrities for online engagement", Online Information Review, Vol. ahead-of-print No. ahead-of-print. https://doi.org/10.1108/ OIR-08-2020-0334

Jackson, A. M., Mullican, L. A., Yin, J., Tse, Z. T. H., Liang, H., Fu, K. W., ... \& Fung, I. C. H. (2018). \# CDCGrandRounds and\# VitalSigns: a Twitter analysis. Annals of global health, 84(4), 710. 
Jeong, B. G., \& Yeo, J. (2018). United Nations and Crisis Management. Global Encyclopedia of Public Administration, Public Policy, and Governance. Cham: Springer International Publishing AG, 6041-6048.

Kumar, S., Huang, B., Cox, R. A. V., \& Carley, K. M. (2021). An anatomical comparison of fake-news and trusted-news sharing pattern on Twitter. Computational and Mathematical Organization Theory, 27(2), 109-133.

Maryland State Department of Education (2013). Text Complexity Clarification and Resource Guide. https://www.stevenson.edu/academics/schools/schoolsciences/stem-initiatives/project-lead-the-way/documents/Text-ComplexityClarification-and-Resource-Guide.pdf adresinden alındı. (Erişim Tarihi: 19.10.2021)

Mozdeh Big Data Text Analysis (2020). mozdeh.wlv.ac.uk adresinden alındı.

Nagel, L. (2020), "The influence of the COVID-19 pandemic on the digital transformation of work", International Journal of Sociology and Social Policy, Vol. 40 No. 9/10, pp. 861-875. https://doi.org/10.1108/IJSSP-07-2020-0323

Pedro Soto-Acosta (2020) COVID-19 Pandemic: Shifting Digital Transformati on to a High-Speed Gear, Information Systems Management, 37(4), 260-266, DOI: 10.1080/10580530.2020.1814461

Pummerer, L., Böhm, R., Lilleholt, L., Winter, K., Zettler, I., \& Sassenberg, K. (2020). Conspiracy theories and their societal effects during the COVID-19 pandemic. Social Psychological and Personality Science, 19485506211000217.

Rath, M., Pati, B., \& Pattanayak, B. K. (2018). An overview on social networking: design, issues, emerging trends, and security. Social Network Analytics: Computational Research Methods and Techniques, 21.

Reuter, C., Kaufhold, M. A., Schmid, S., Spielhofer, T., \& Hahne, A. S. (2019). The impact of risk cultures: Citizens' perception of social media use in emergencies across Europe. Technological Forecasting and Social Change, 148(1), 1-17.

Riffe, D., Lacy, S., Watson, B. R., \& Fico, F. (2019). Analyzing media messages: Using quantitative content analysis in research. New York: Routledge.

Sehl, K. (2020). How the Twitter Algorithm Works in 2020 and How to Make it Work for You. https://blog.hootsuite.com/twitter-algorithm/ adresinden alındı.

Shugars, S., \& Beauchamp, N. (2019). Why keep arguing? Predicting engagement in political conversations online. Sage Open, 9(1), 2158244019828850.

Suh, B., Hong, L., Pirolli, P., \& Chi, E. H. (2010, August). Want to be retweeted? large scale analytics on factors impacting retweet in twitter network. In 2010 IEEE second international conference on social computing (pp. 177-184). IEEE.

Starbird, K., \& Palen, L. (2011, May). "Voluntweeters" self-organizing by digital volunteers in times of crisis. In Proceedings of the SIGCHI conference on human factors in computing systems (pp. 1071-1080). 
Teyit.org (2018). Aşı karşıtlığı ve Covid-19. https://teyit.org/dosya-asi-karsitligi-vecovid-19 adresinden alındı. (Erişim Tarihi: 17.10.2021)

Tsur, O., \& Rappoport, A. (2012, February). What's in a hashtag? Content based prediction of the spread of ideas in microblogging communities. In Proceedings of the fifth ACM international conference on Web search and data mining (pp. 643-652).

Twitter (2020). Platform manipülasyonu ve spam politikası. https://help.twitter.com/tr/ rules-and-policies/platform-manipulation adresinden alındı.

Uscinski, J. E., Enders, A. M., Klofstad, C., Seelig, M., Funchion, J., Everett, C., ... \& Murthi, M. (2020). Why do people believe COVID-19 conspiracy theories?. Harvard Kennedy School Misinformation Review, 1(3).

Valencia, S. W., Wixson, K. K., \& Pearson, P. D. (2014). Putting text complexity in context: Refocusing on comprehension of complex text. The Elementary School Journal, 115(2), 270-289.

Wang, R., Liu, W., \& Gao, S. (2016). Hashtags and information virality in networked social movement: Examining hashtag co-occurrence patterns. Online Information Review.

Weigmann, K. (2018). The genesis of a conspiracy theory: Why do people believe in scientific conspiracy theories and how do they spread?. EMBO reports, 19(4), e45935.

White, M. D., \& Marsh, E. E. (2006). Content analysis: A flexible methodology. Library trends, 55(1), 22-45.

Whittaker, J., Handmer, J., \& McLennan, B. (2015). Informal volunteerism in emergencies and disasters: a literature review. Melbourne, Australia: Bushfire and Natural Hazards CRC.

Żyłka, K. (2018). Shorter or longer tweets? One year with the expanded character limit [analysis]. https://www.sotrender.com/blog/2018/10/shorter-longer-tweets-one-year-expanded-character-limit-analysis adresinden alındı. (Erişim Tarihi: 15.10.2021) 